\begin{tabular}{ll|l} 
Case Reports in & \multicolumn{2}{c}{ Case Rep Gastroenterol 2019;13:78-84 } \\
\cline { 2 - 3 } Gastroenterology & $\begin{array}{l}\text { DOl: 10.1159/000497098 } 2019 \text { The Author(s) } \\
\text { Published online: February 15, } 2019\end{array}$ & $\begin{array}{l}\text { Published by S. Karger AG, Basel } \\
\text { www.karger.com/crg }\end{array}$ \\
\cline { 2 - 3 } & $\begin{array}{l}\text { This article is licensed under the Creative Commons Attribution-NonCommercial } 4.0 \\
\text { International License (CC BY-NC) (http://www.karger.com/Services/OpenAccessLicense). } \\
\text { Usage and distribution for commercial purposes requires written permission. }\end{array}$
\end{tabular}

\title{
Laparoscopic Resection of an Abdominal Wall Metastasis 5 Years after Primary Colorectal Cancer Resection
}

\author{
Ryota Koyama Yoshiaki Maeda Nozomi Minagawa Toshiki Shinohara \\ Tomonori Hamada \\ Department of Gastrointestinal Surgery, Hokkaido Cancer Center, Sapporo, Japan
}

\section{Keywords}

Abdominal wall metastasis $\cdot$ Colorectal cancer $\cdot$ Laparoscopic surgery

\begin{abstract}
We report the case of a 65-year-old male with a metachronous abdominal wall metastasis secondary to colorectal cancer. The patient had presented 5 years ago to another facility with a perforated sigmoid colon cancer (pT4a[SE], N0, M0, pStage II), rectal cancer (T2[MP], N0, M0, pStage I), and Fournier gangrene. He had then undergone sigmoidectomy and rectal resection along with S-1 adjuvant chemotherapy. No relapse was observed thereafter. However, currently, 5 years after initial surgery, the patient noticed a palpable mass in the left lower abdomen and was referred to our hospital for further assessment and treatment. Percutaneous echo-guided needle biopsy of the tumor revealed an adenocarcinoma tissue. Following 6 courses of FOLFOX plus cetuximab chemotherapy, laparoscopic resection for abdominal wall metastasis was successfully performed. The resected tissue was pathologically characterized as adenocarcinoma, which was compatible with the recurrence of the primary colorectal carcinoma resected 5 years ago. The abdominal wall metastasis was attributed to the cancer cell implantation secondary to the perforated sigmoid colon cancer treated 5 years ago.
\end{abstract}




\section{Case Reports in Gastroenterology}

Case Rep Gastroenterol 2019;13:78-84

DOI: 10.1159/000497098

(c) 2019 The Author(s). Published by S. Karger AG, Basel www.karger.com/crg

Koyama et al.: Laparoscopic Resection of an Abdominal Wall Metastasis 5 Years after Primary Colorectal Cancer Resection

\section{Introduction}

Abdominal wall metastasis is a rare form of metastatic colorectal cancer (CRC). CRC often metastasizes to the liver, lung, and other distant organs through lymphatic and hematogenous routes. On the other hand, metastasis in the form of cancer cell implantation in the peritoneum, anastomosis site, surgical incision site, or drain site are relatively rare [1]. Here, we report a case of successful laparoscopic resection of an abdominal wall metastasis attributable to cancer cell implantation from a perforated sigmoid colon cancer that was resected 5 years ago. We describe the case in detail and discuss pertinent literature.

\section{Case Presentation}

The 65-year-old male patient had initially presented with a strangulated left inguinal hernia and a perforated sigmoid colon cancer 5 years ago at another facility. Computed tomography (CT) imaging that had been conducted showed abscess formation and air density from the left inguinal region to the left lower abdominal wall, indicating Fournier gangrene formation (Fig. 1a). Hernia reduction and abscess drainage were performed, and a colonoscopy conducted after surgery revealed advanced sigmoid colon and rectal cancers. Further, 2 weeks after the initial surgery, a sigmoidectomy and rectal resection with lymph node dissection were performed, and the tumors were pathologically staged as sigmoid colon cancer (Type3, tub1, pT4a[SE], ly1, v0, N0, M0, pStage II) and rectal cancer (Type2, tub2, T2[MP], ly2, v1, N0, M0, pStage I). Additionally, S-1 adjuvant chemotherapy was administered for 1 year, and no recurrence was observed during regular follow-up. Currently, 5 years after primary cancer resection, the patient became aware of a palpable left lower abdominal mass that was increasing in size. The contrast-enhanced CT performed at another facility revealed an enhanced mass in the left abdominal wall (Fig. 1b), following which he was referred to our facility for further assessment and treatment of a palpable mass. A percutaneous echo-guided needle biopsy identified the tissue as an adenocarcinoma with an atypical tubular epithelium. Laboratory data showed slightly elevated AST level (65 IU/L). ALT was normal (35 IU/L), and other data remained unremarkable, including normal levels of tumor markers (CEA $2.3 \mathrm{ng} / \mathrm{mL}$, CA19-9 $17 \mathrm{U} / \mathrm{mL}$ ). The contrast-enhanced CT revealed a well-circumscribed left lower abdominal intramuscular mass measuring $50 \times 30 \mathrm{~mm}$ (Fig. 1b); no peritoneal dissemination, ascites, or distant-organ metastasis were detected. Based on these findings, the preoperative diagnosis was a solitary metachronous abdominal wall metastasis, and the treatment plan entailed tumor resection following preoperative chemotherapy using FOLFOX plus cetuximab. After 6 courses of chemotherapy, no considerable reduction in tumor size was noted; more importantly, no other signs of recurrence were observed, and laparoscopic resection was performed as described below. The patient was placed in the supine position, and the first 12$\mathrm{mm}$ trocar was placed in the right side of the abdomen using Hasson's technique. Under $\mathrm{CO}_{2}$ insufflation at a pressure of $8 \mathrm{~mm} \mathrm{Hg}$, two additional 5-mm trocars were placed in the right side of the abdomen caudal to the 12-mm trocar with one of them being used for the camera. The assistant surgeon operated through a 5-mm trocar placed in the left upper abdominal area. Intraabdominal adhesions were observed but dissected easily, and laparoscopic surveillance of the entire abdominal space, including the peritoneum and the liver, revealed no signs of distant metastasis. Intraabdominal lavage fluid was negative for cytology. The tumor was visible as a mass covered by a normal peritoneum (Fig. 2a). A surgical margin of $2 \mathrm{~cm}$ along the tumor contour was marked using a dye guided by external palpation (Fig. 2b). An entire 


\section{Case Reports in Gastroenterology}

Case Rep Gastroenterol 2019;13:78-84

DOI: 10.1159/000497098

(c) 2019

www.karger.com/crg

Koyama et al.: Laparoscopic Resection of an Abdominal Wall Metastasis 5 Years after Primary Colorectal Cancer Resection

circumferential incision of the peritoneum was performed using laparoscopic coagulating shears and electric cautery (Fig. 2c), and the depth of the incision was set at the level of subcutaneous fat tissue, with no exposure of skin to prevent cutaneous ischemia and necrosis. On achieving this depth through incision of the rectus muscle, subcutaneous fat was horizontally dissected to reach the other side of the tumor margin. The left hypogastric vessels were clipped and cut, and the tumor was carefully isolated from the abdominal wall without causing any damage to the tumor capsule. The resultant abdominal wall defect measuring $8 \mathrm{~cm}$ was covered with skin and subcutaneous tissue (Fig. 2d) but was left unreconstructed. The procedure lasted $132 \mathrm{~min}$, and blood loss was $0 \mathrm{~mL}$. The resected specimen was a poorly marginated, whitish, nodular lesion measuring $5 \times 3.5 \times 1.5 \mathrm{~cm}$ (Fig. 3a, b) that was pathologically characterized as an adenocarcinoma with irregular proliferations and a fused ductal structure (Fig. 3c). Moreover, calcification was observed, and immunohistochemistry revealed CDX-2 positivity (Fig. 3d). Based on these findings, a diagnosis of metastatic CRC was established. The patient developed an abdominal hernia. No other complications associated with surgery developed subsequently; the patient required no additional treatment after surgery, and no recurrence was observed during an 8-month follow-up period.

\section{Discussion}

Abdominal wall metastasis secondary to CRC is often considered an end-stage presentation, and a solitary metastasis is rare. Abdominal wall metastasis can be caused by direct invasion, lymphatic routes, hematogenous routes, and cancer cell implantation [1]. In the present case, it was considered that the cancer cells were implanted into the abdominal wall either via the perforated sigmoid colon cancer or through the drain placed during previous surgery. However, the drain scar could not be confirmed, and the observed discrepancy between the position of the recurrence site and the drain route determined by CT imaging suggested that the drain site being the etiological factor is unlikely. Therefore, the metastasis was attributed to cancer cell dissemination secondary to the perforated sigmoid colon cancer and the development of Fournier gangrene 5 years ago. Although there are reports of rectal cancer with Fournier gangrene [2], we found no reports of abdominal wall recurrence originating from such an inflammation. Further, we searched the PubMed database for case reports of laparoscopic resection of abdominal wall metastasis using the keywords "abdominal wall," "metastasis," "recurrence," and "laparoscopic resection"; however, we were unable to find any relevant reports. One probable reason is that abdominal wall metastasis typically presents as cutaneous metastasis in the shallow part of the abdominal wall. Therefore, any genuine "intramuscular" abdominal wall metastases are considered rare occurrences. To the best of our knowledge, this is the first report on laparoscopic resection of an abdominal wall metastasis. We chose to laparoscopically resect the abdominal wall metastasis because of advantages, such as smaller incision, lower pain, and faster recovery [3], associated with laparoscopic surgery along with the clinical advantage of being able to assess the abdomen for other metastases. This is particularly relevant in patients with advanced cancer who are at a higher risk of developing noncurable factors, such as peritoneal dissemination. Further, in such patients, the intraoperative decision of whether to proceed or cease the procedure is determined in the initial phase to prevent unnecessary invasion. Abdominal wall defects following tumor resection are typically repaired using direct sutures or mesh implantation. A previous randomized study on incisional hernias has revealed that mesh repair resulted in lower hernia recurrence than suture repair and that hernia size is not associated with the rate of recurrence [4]. 
Therefore, although we initially sought to reconstruct the abdominal wall defect with a mesh, we chose not to do so during the procedure because the defect was larger than expected; moreover, we suspected that the mesh might put the patient at risk of a strangulating hernia. With informed consent obtained prior to surgery on the resected part of the abdomen becoming distended following surgery, the patient tolerated an abdominal hernia with no major associated complications occurring subsequently. In several cases with a solitary abdominal wall metastasis of CRC, resection is generally attempted only if no other distant metastases exist. Our case report suggests that laparoscopic resection is a feasible treatment method for solitary abdominal wall metastasis. However, it must be ensured that the patient is tolerant and consents to the resulting abdominal hernia.

\section{Statement of Ethics}

The authors have no ethical conflicts to disclose.

\section{Disclosure Statement}

The authors have no conflicts of interest to declare.

\section{References}

1 Reilly WT, Nelson H, Schroeder G, Wieand HS, Bolton J, O'Connell MJ. Wound recurrence following conventional treatment of colorectal cancer. A rare but perhaps underestimated problem. Dis Colon Rectum. 1996 Feb;39(2):200-7.

2 Bruketa T, Majerovic M, Augustin G. Rectal cancer and Fournier's gangrene - current knowledge and therapeutic options. World J Gastroenterol. 2015 Aug;21(30):9002-20.

3 Rivas H, Díaz-Calderón D. Present and future advanced laparoscopic surgery. Asian J Endosc Surg. 2013 May;6(2):59-67.

4 Luijendijk RW, Hop WC, van den Tol MP, de Lange DC, Braaksma MM, IJzermans JN, et al. A comparison of suture repair with mesh repair for incisional hernia. N Engl J Med. 2000 Aug;343(6):392-8. 


\section{Case Reports in Gastroenterology}

\begin{tabular}{l|l}
\hline Case Rep Gastroenterol 2019;13:78-84 \\
\hline DOI: 10.1159/000497098 & $\begin{array}{l}\text { ○ 2019 The Author(s). Published by S. Karger AG, Basel } \\
\text { www.karger.com/crg }\end{array}$ \\
\hline
\end{tabular}
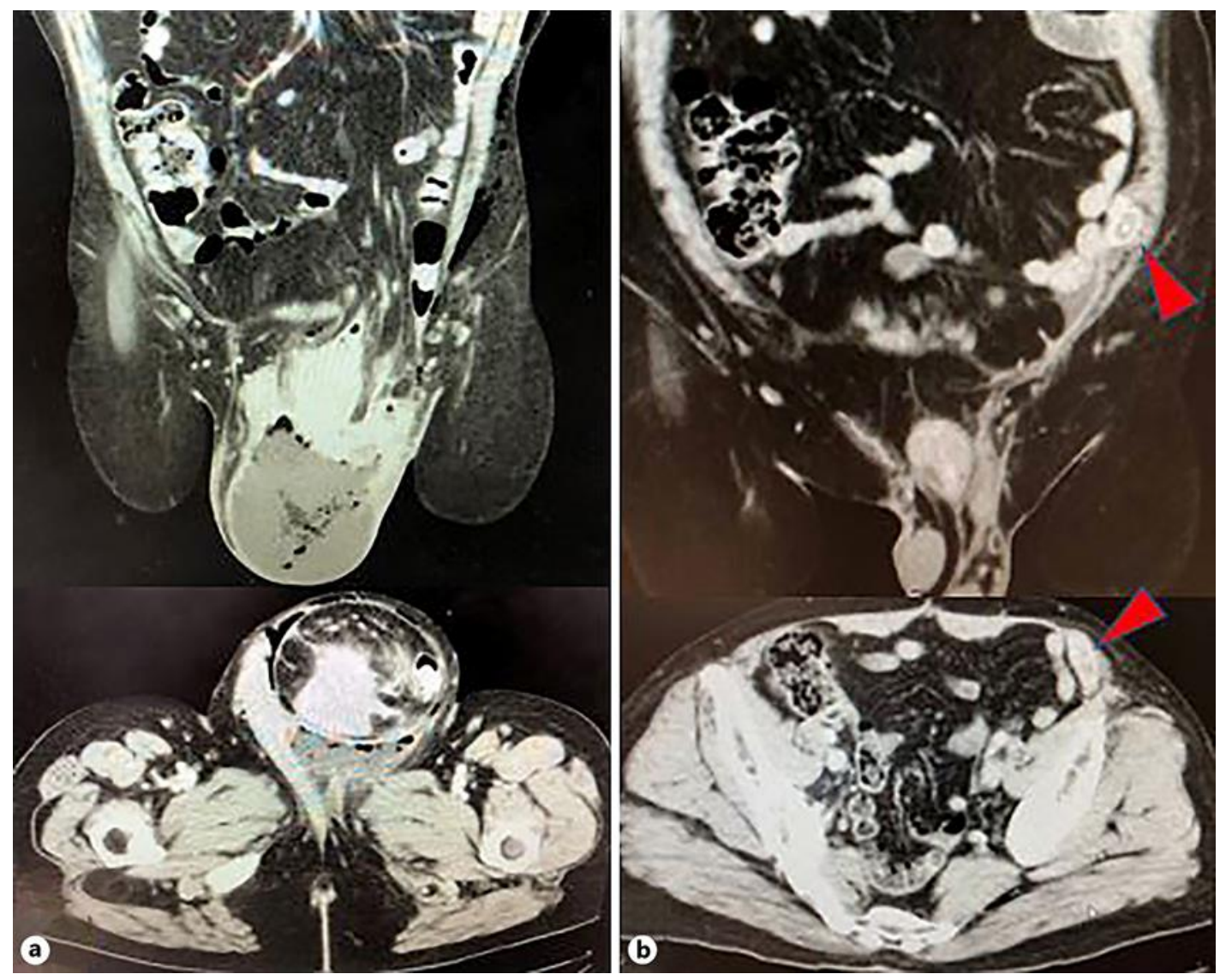

Fig. 1. Computed tomography findings. The perforated sigmoid colon cancer and Fournier gangrene observed 5 years ago (a) and the current abdominal wall metastasis (arrowhead) near the left inguinal region (b). 


\section{Case Reports in Gastroenterology}

\begin{tabular}{l|l}
\hline Case Rep Gastroenterol 2019;13:78-84 \\
\hline DOI: 10.1159/000497098 & $\begin{array}{l}\text { ○ 2019 The Author(s). Published by S. Karger AG, Basel } \\
\text { www.karger.com/crg }\end{array}$ \\
\hline
\end{tabular}

Koyama et al.: Laparoscopic Resection of an Abdominal Wall Metastasis 5 Years after Primary Colorectal Cancer Resection
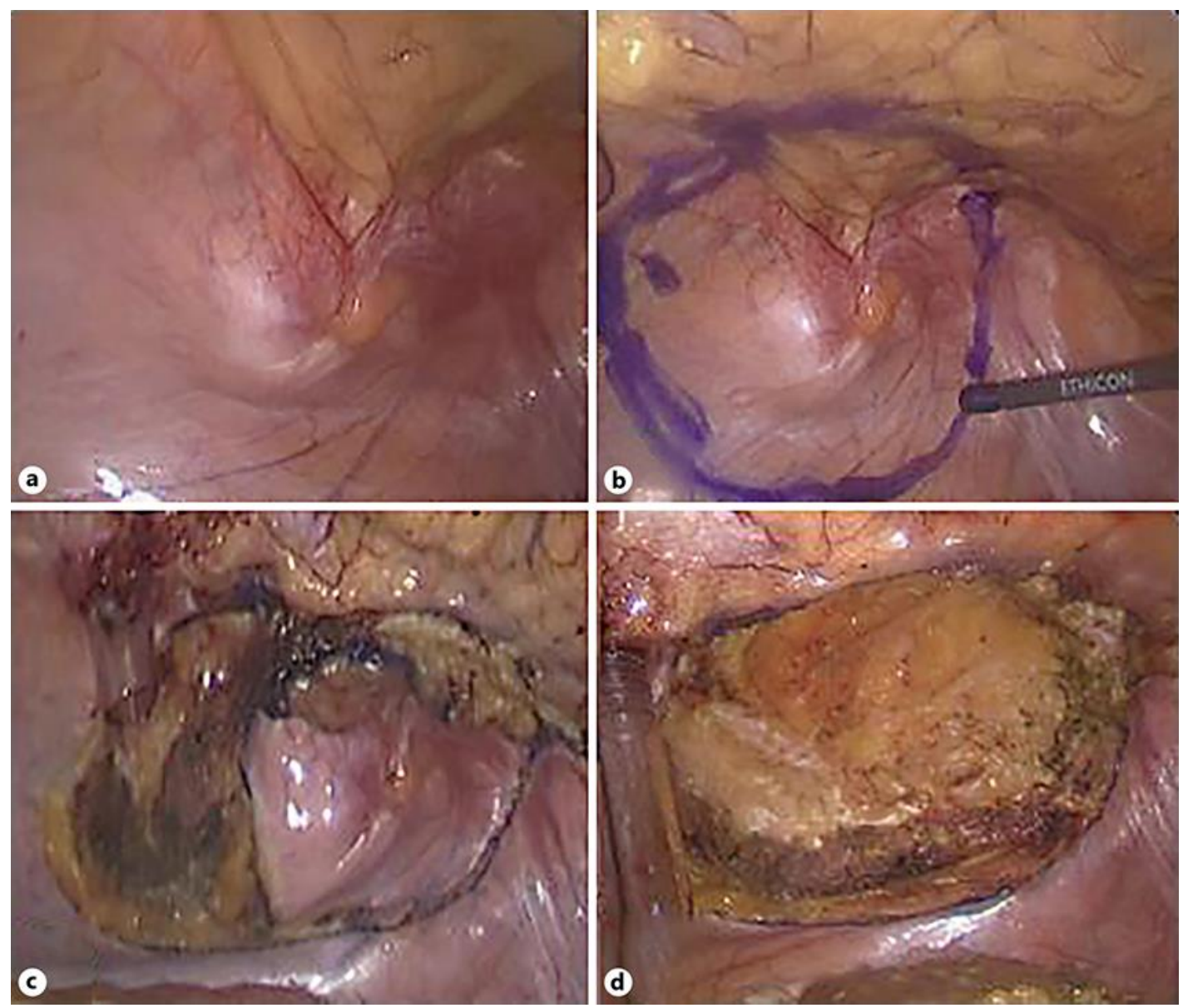

Fig. 2. Intraoperative findings. Abdominal wall metastasis is observed as a mass covered with normal peritoneum (a). A surgical margin of $2 \mathrm{~cm}$ along the tumor contour is marked using a dye (b). An entire circumferential incision of the peritoneum is performed for tumor resection (c), and the resulting abdominal wall defect is approximately $8 \mathrm{~cm}$ in diameter (d). 


\section{Case Reports in Gastroenterology}

\begin{tabular}{l|l}
\hline Case Rep Gastroenterol 2019;13:78-84 \\
\hline DOI: 10.1159/000497098 & $\begin{array}{l}\text { @ 2019 The Author(s). Published by S. Karger AG, Basel } \\
\text { www.karger.com/crg }\end{array}$ \\
\hline
\end{tabular}

Koyama et al.: Laparoscopic Resection of an Abdominal Wall Metastasis 5 Years after Primary Colorectal Cancer Resection
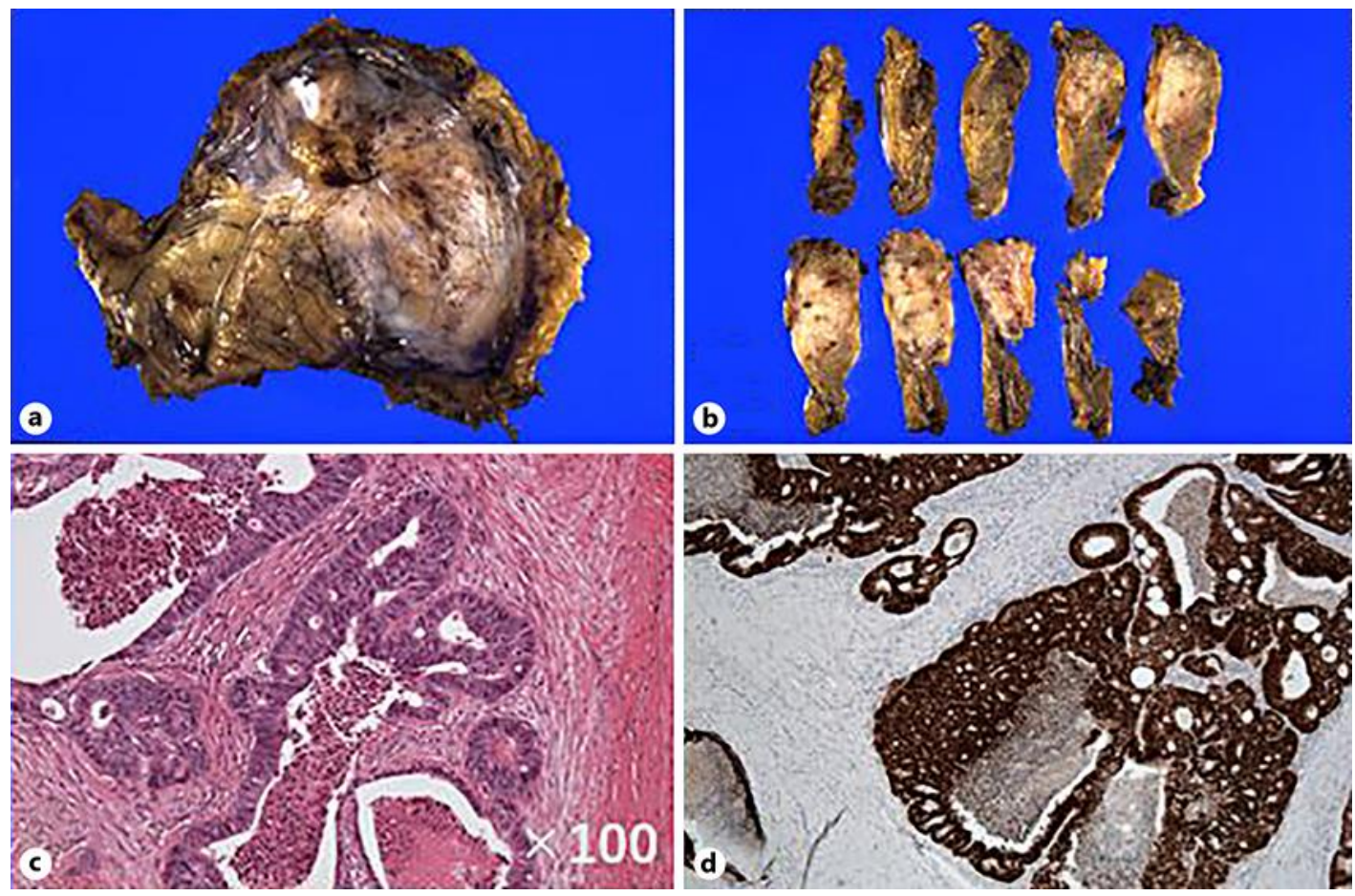

Fig. 3. Tumor specimen and pathological findings. The resected specimen is a poorly marginated, whitish, nodular lesion measuring $5 \times 3.5 \times 1.5 \mathrm{~cm}(\mathbf{a}, \mathbf{b})$ that was pathologically characterized as an adenocarcinoma with irregular and fused ductal structure, similar to the colorectal adenocarcinoma (c). HE. $\times 100$. The immunohistochemical staining was positive for CDX-2 (d). 